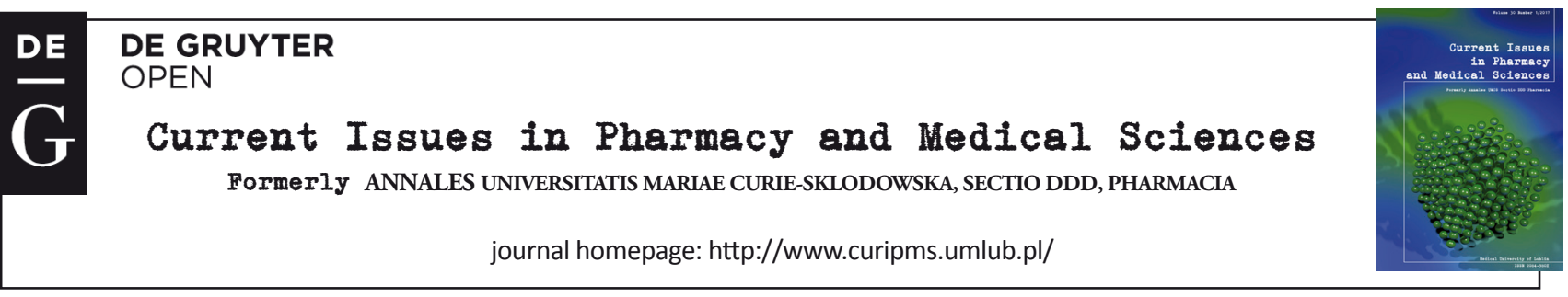

\title{
Risk factors of gestational hypertension development
}

\author{
Olga Bulavenko ${ }^{1}$, OKsana Vaskiv ${ }^{2 *}$ \\ ${ }^{1}$ Department of Obstetrics and Gynecology №2 National Pirogov Memorial Medical University,Vinnytsya, Pirogov 56, 21018 Vinnytsya, \\ Ukraine \\ 2 Post-graduate Department of Obstetrics and Gynaecology; Post-Qualifying Education National Pirogov Memorial Medical University, \\ Vinnytsya, Vodoprovidna 8/1 29000 Khmelnitskiy, Ukraine
}

\section{ARTICLE INFO}

Received 21 April 2017

Accepted 03 July 2017

\section{Keywords:}

gestational hypertension,

pregnancy,

risk factors.

\begin{abstract}
The problem of gestational hypertension $(\mathrm{GH})$ remains to be of current concern in obstetric practice. The purpose of this study, therefore, was to determine the risk factors for $\mathrm{GH}$ development. We examined 53 pregnant women and allocated them to 2 groups: the main group - pregnant women with gestational hypertension $(n=30)$ and the control group - pregnant women without the pathology $(n=23)$. The selection of persons for the study was carried out on the basis of detailed history taking, examination and complaints, using standard clinical, laboratory and instrumental methods of investigation. The data was processed on a PC (standard statistical package Statistica 6.0). Our results show that the gestational hypertension development is closely linked with such risk factors as: age $\leq$ 18 years old and over 35 years old, unmarried status, living in a city/town, post-secondary education, unemployment, obesity, first labor in consecutively pregnant women, the threat of pregnancy termination, cardiovascular system diseases, urinary tract pathology, varicose veins, as well as $\mathrm{ABO}$-sensibilization.
\end{abstract}

\section{INTRODUCTION}

The problem of abnormal pregnancy, including gestational hypertension $(\mathrm{GH})$, is one of the burning problems in obstetric practice. Preeclampsia and GH leads to the development of multiple organ failure and to progressive deterioration that prevents pregnancy prolongation. Indeed, many authors consider it to have a much greater negative impact on the mother and fetus condition than a chronic increase in blood pressure (BP) as this, when adjusted, does not cause the target organ damage $[5,6]$. GH is the most common hypertensive disorder induced by pregnancy. The onset of hypertension is defined by: systolic blood pressure $\geq 140 \mathrm{mmHg}$ and/or diastolic blood pressure $\geq 90 \mathrm{mmHg}$ at $\geq 20$ weeks of gestation in the absence of proteinuria.

$\mathrm{GH}$ is more frequent in primipregnant women. Some authors consider such GH risk factors to be: age -28 years old and older, being overweight before pregnancy and having a history of episodes of increased BP $[3,4]$. Norvitts and D. Sharjah name the following risk factors of Acute $\mathrm{GH}$ : young pregnancy age $(<15$ years old) and age $>35$ years old; primipregnancy, gestational hypertension and preeclampsia in family history; collagenoses; T235 gene mutation encoding angiotensinogen; antiphospholipid

\footnotetext{
* Corresponding author

e-mail: vavilon1985@gmail.com
}

syndrome (APS); multiple pregnancy, as well as accommodation in the city [1].

The problem of pregnant women obesity has become urgent because of the risk of serious maternal, fetal and neonatal complications [8]. Women who are overweight $\left(\mathrm{BMI}>29 \mathrm{~kg} / \mathrm{m}^{2}\right)$ have a high risk of $\mathrm{GH}$ development. Moreover, preeclampsia manifests more often in pregnant women with super overweight $\left(B M I>50 \mathrm{~kg} / \mathrm{m}^{2}\right)$, while the risk of perinatal complications significantly increases, compared with mothers having a lower BMI $[2,7]$.

Despite the achievements in the study of various aspects of the gestosis pathogenesis and the development of new diagnostic methods, there is no significant progress in treatment effectiveness enhancing and in complications prevention.

The purpose of this study was to determine the risk factors for $\mathrm{GH}$ development.

\section{MATERIALS AND METHODS}

In order to determine the risk factors for $\mathrm{GH}$, we examined 83 pregnant women living in the Khmelnitsky region. The patients were then allocated to two groups: the main group - pregnant women with GH $(n=48)$; and the control group - which consisted of pregnant women without 
the pathology $(n=35)$. The selection of persons for the study was carried out on the basis of detailed history, examination and complaint, using standard clinical, laboratory and instrumental methods of investigation. The data was processed on a PC, using a standard statistical package - Statistica 6.0.

To determine risk factors $\mathrm{GH}$, we used the relative risk (RR) and odds ratio (OR). The relative risk is given by

$$
\mathrm{RR}=\frac{\text { Risk of event in the Treatment group }}{\text { Risk of event in the Control group }}=\frac{\mathrm{a} /(\mathrm{a}+\mathrm{b})}{\mathrm{c} /(\mathrm{c}+\mathrm{d})},
$$
where:

$\mathrm{RR}$ - relative risk,

$\mathrm{a}-$ the number of pregnant women with positive (bad) result in the study group,

$\mathrm{b}$ - the number of pregnant women with negative (good) result in the study group,

$\mathrm{c}$ - the number of pregnant women with positive (bad) result in the control group,

$\mathrm{d}$ - the number of pregnant women with negative (good) result in the control group.

The standard error of the log relative risk being:

$$
\mathrm{SE}\{\ln (R R)\}=\sqrt{\frac{1}{\mathrm{a}}+\frac{1}{\mathrm{c}}+\frac{1}{\mathrm{a}+\mathrm{b}}+\frac{1}{\mathrm{c}+\mathrm{d}}}
$$

95\% confidence interval:

$$
\begin{gathered}
95 \% \mathrm{Cl}=\exp (\ln (R R)-1.96 \times \mathrm{SE}\{\ln (R R)\}) \text { to } \\
\exp (\ln (R R)+1.96 \times \mathrm{SE}\{\ln (R R)\})
\end{gathered}
$$

The odds ratio is given by $\mathrm{OR}=\frac{\text { Odds of event in the Treatment group }}{\text { Odds of event in the Control group }}=\frac{\mathrm{a} / \mathrm{b}}{\mathrm{c} / \mathrm{d}}=\mathrm{ad} / \mathrm{bc}$, where:

$\mathrm{RR}$ - odds ratio,

a - the number of pregnant women with positive (bad) result in the study group,

$\mathrm{b}$ - the number of pregnant women with negative (good) result in the study group,

$\mathrm{c}$ - the number of pregnant women with positive (bad) result in the control group,

$\mathrm{d}$ - the number of pregnant women with negative (good) result in the control group.

The standard error of the log odds ratio being:

$$
\mathrm{SE}\{\ln (O R)\}=\sqrt{\frac{1}{\mathrm{a}}+\frac{1}{\mathrm{~b}}+\frac{1}{\mathrm{c}}+\frac{1}{\mathrm{~d}}}
$$

95\% confidence interval:

$$
\begin{gathered}
95 \% \mathrm{Cl}=\exp (\ln (O R)-1.96 \times \mathrm{SE}\{\ln (O R)\}) \text { to } \\
\exp (\ln (O R)+1.96 \times \mathrm{SE}\{\ln (O R)\})
\end{gathered}
$$

The study was approved by the Bioethics Committee of the National Pirogov Memorial Medical University, Vinnytsya (2015).

\section{RESULTS}

Age factor: The women with GH were aged 17 to 38 years old, the average age in the group $-25.3 \pm 7.6$ years old. Categorized by age: before 18 years old -6 woman (12.5\%), 19 to 30 years old - 29 women $(60.4 \%), 31$ to 35 years old -7 women $(14.6 \%)$, over 35 years old -6 women $(12.5 \%)$.
The women in the control group were aged 18 to 36 years old, the average age $-24 \pm 4,4$ years old. Categorized by age: before 18 years old -2 women $(5.7 \%), 19$ to 30 years old -20 women $(80.0 \%), 31$ to 35 years old -3 women $(8.6 \%)$, over 35 years old -2 woman $(5.7 \%)$.

Three risk factors relating to the age of the mother were evaluated to predict GH development: age $\leq 18$ years old,

\begin{tabular}{|c|c|c|c|c|}
\hline Risk Factors & $\begin{array}{c}\text { Relative } \\
\text { risk } \\
\text { (RR) }\end{array}$ & $\begin{array}{c}95 \% \\
\text { confidence } \\
\text { interval for } \\
\text { RR }\end{array}$ & $\begin{array}{l}\text { Odds } \\
\text { ratio } \\
\text { (OR) }\end{array}$ & $\begin{array}{c}95 \% \\
\text { confidence } \\
\text { interval for } \\
\text { OR }\end{array}$ \\
\hline \multicolumn{5}{|l|}{ Age: } \\
\hline$\leq 18$ years old & 2.18 & $0.47-10.2$ & 2.35 & $0.44-12.4$ \\
\hline $19-30$ years old & 1.05 & $0.73-1.52$ & 1.14 & $0.47-2.77$ \\
\hline $31-35$ years old & 1.70 & $0.47-6.12$ & 1.82 & $0.43-7.60$ \\
\hline over 35 years old & 2.18 & $0.47-10.2$ & 2.35 & $0.44-12.4$ \\
\hline \multicolumn{5}{|l|}{ Marital status: } \\
\hline Married & 0.91 & $0.77-1.07$ & 0.46 & $0.11-1.91$ \\
\hline Not married & 1.94 & $0.55-6.80$ & 2.13 & $0.52-8.70$ \\
\hline \multicolumn{5}{|l|}{ Education: } \\
\hline Secondary & 1.27 & $0.40-4.02$ & 1.32 & $0.35-4.92$ \\
\hline Post Secondary & 1.34 & $0.94-1.90$ & 2.26 & $0.90-5.69$ \\
\hline Higher & 0.36 & $0.15-0.87$ & 0.27 & $0.09-0.82$ \\
\hline \multicolumn{5}{|l|}{ Place of residence } \\
\hline City & 1.17 & $0.97-1.40$ & 3.75 & $0.89-15.70$ \\
\hline Village & 0.31 & $0.08-1.12$ & 0.26 & $0.06-1.11$ \\
\hline Employed & 0.64 & $0.37-1.10$ & 0.48 & $0.19-1.18$ \\
\hline Unemployed & 1.33 & $0.91-1.94$ & 2.07 & $0.84-5.11$ \\
\hline \multicolumn{5}{|l|}{ Parity: } \\
\hline Primipregnancy & 0.82 & $0.57-1.17$ & 0.61 & $0.25-1.51$ \\
\hline Consecutive pregnancy & 1.33 & $0.76-2.32$ & 1.62 & $0.65-3.98$ \\
\hline $\begin{array}{l}\text { Consecutive pregnancy, } \\
\text { first labor }\end{array}$ & 1.60 & $0.61-4.20$ & 1.78 & $0.55-5.69$ \\
\hline $\begin{array}{l}\text { Consecutive pregnancy, } \\
\text { re-birth }\end{array}$ & 1.14 & $0.49-2.65$ & 1.18 & $0.40-3.45$ \\
\hline $\begin{array}{l}\text { Gestational hypertension } \\
\text { history }\end{array}$ & 2.72 & $0.35-20.73$ & 3.23 & $0.33-31.53$ \\
\hline \multicolumn{5}{|l|}{ BMI: } \\
\hline $18,5-24,9 \mathrm{~kg} / \mathrm{m}^{2}$ & 0.46 & $0.31-0.70$ & 0.15 & $0.05-0.41$ \\
\hline $25-29,9 \mathrm{~kg} / \mathrm{m}^{2}$ & 1.75 & $0.67-4.51$ & 2.00 & $0.63-6.31$ \\
\hline$>30 \mathrm{~kg} / \mathrm{m}^{2}$ & 6.56 & $1.62-26.46$ & 9.90 & $2.11-46.28$ \\
\hline The threat of miscarriage & 2.79 & $1.27-6.13$ & 4.44 & $1.56-12.65$ \\
\hline
\end{tabular}
31 to 35 years old and over 35 years old. Women aged $\leq 18$ years old have the relative risk of $\mathrm{GH}-2.18$, aged $31-35$ years old -1.70 , over 35 years old -2.18 (Table 1 ). Women aged $\leq 18$ years old and over 35 years old had the higher risk of $\mathrm{GH}$ development.

Table 1. Risk factors of gestational hypertension development

Marital status: GH group: 40 women were married $(84.4 \%)$, unmarried -8 women $(16.6 \%)$. In the control group: 32 women were married $(91.4 \%)$, unmarried $3(8.6 \%)$. The chance of GH development is higher in unmarried women (RR - 1.94 and $\mathrm{OR}-2.13)$.

Level of completed formal education: GH group: secondary education -7 women $(14,6 \%)$, post secondary education -35 women $(72.9 \%)$, higher education -6 women $(12.5 \%)$. In the control group: secondary education -4 women $(11.4 \%)$, post-secondary - 19 women $(54.3 \%)$, higher education - 12 women $(34.3 \%)$. The chances of GH development in pregnant women with post secondary education are higher (2.26 times), while women with higher education have the lowest chances.

Place of residence: Among the women with GH: 3 lived in the village (6.2\%) and 45 lived in the city (94.8\%). In the control group: 7 lived in the village $(20 \%)$ and 28 lived in the city $(80 \%)$. The relative risk of GH development in pregnant women who live in urban areas is 1.17 and the chances of GH development in pregnant women who live in rural areas increases 3.75 times. 
Employment: GH group: 15 women were employed $(31,3 \%), 5$ women $(10,4 \%)$ studied and 28 women $(58.3 \%)$ were family carers. In the control group: 17 women $(48.6 \%)$ were employed, 6 woman $(17.1 \%)$ studied and 12 women $(34.3 \%)$ were family carers. The family carers have the higher chances of GH development (x 2.07 times).

Parity: GH group: primipregnancy - 26 (54.2\%) women, consecutive pregnancy - 22 (45.8). In the control group: primipregnancy - $23(65,7 \%)$, consecutive pregnancy 12 (34.3). GH group: first-born women - 37 women (77.1\%), re-birth women - $11(22.9 \%)$. In the control group: first-born women $-28(80 \%)$, re-birth women $-7(20 \%)$. The highest risk of GH development was in consecutively pregnant and in first-born women (RR - 1.60, OR - 1.78).

GH history: GH group: 5 (22.7\%), control group: $1(8.3 \%)$ (RR - 2.72, OR - 3.23).

BMI: The average BMI in the early pregnancy period of the $\mathrm{GH}$ group was $29.78 \mathrm{~kg} / \mathrm{m}^{2}$, in the control group $21.86 \mathrm{~kg} / \mathrm{m}^{2}$. Moreover, $18(37.5 \%)$ women of the GH group and $28(80.0 \%)$ in the control group had BMI $18.5-24.9 \mathrm{~kg} / \mathrm{m}^{2}$, and $12(25 \%)$ and $5(14.3 \%)$ women, respectively, had BMI $25.0-29.9 \mathrm{~kg} / \mathrm{m}^{2}$, while $18(37.5 \%)$ women of the GH group and $2(5,7 \%)$ women in the control group had BMI $>$ $30 \mathrm{~kg} / \mathrm{m}^{2}$. When BMI in early pregnancy is $>30 \mathrm{~kg} / \mathrm{m}^{2}$, the risk of $\mathrm{GH}$ development is the highest -6.56 , and while BMI is $18.5-24.9 \mathrm{~kg} / \mathrm{m}^{2}-$ it is the lowest.

Miscarriage: Women with GH had more frequently threatened miscarriage $(23-47.9 \%)$, compared with the control group $(6-17.1 \%)$. Accordingly, the chances of GH development are higher by 4.44 times.

Cardiovascular system pathology: Diseases of the cardiovascular system have been found in $24(50 \%)$ women, among them: 9 (18.7\%) cases - vegetative-vascular dystonia (VVD) of the hypertensive type, $5(10.4 \%)$ - VVD of the mixed type, 2 patients had varicose veins of the lower limbs (4.1\%), $6(12.5 \%)$ - diagnosed with mitral valve prolapse (MVP), 2 (4.1\%) patients - hypertensive disease (Table 2). In the control group, 3 women $(8.6 \%)$ had diseases of the cardiovascular system - mitral valve prolapse. The risk of $\mathrm{GH}$ development in the pathology of cardiovascular system was higher in women with VVD of hypertonic type and VVD of the mixed type (13.95 and 8.08, respectively).

Table 2. Extragenital pathology with gestational hypertension

\begin{tabular}{|l|c|c|c|c|}
\hline \multicolumn{1}{|c|}{ Somatic pathology } & $\begin{array}{c}\text { Relative } \\
\text { risk } \\
\text { (RR) }\end{array}$ & $\begin{array}{c}95 \% \\
\text { confidence } \\
\text { interval }\end{array}$ & $\begin{array}{c}\text { Odds } \\
\text { ratio } \\
\text { (OR) }\end{array}$ & $\begin{array}{c}95 \% \\
\text { confidence } \\
\text { interval for } \\
\text { OR }\end{array}$ \\
\hline $\begin{array}{l}\text { Cardiovascular system } \\
\text { pathology: }\end{array}$ & & & & \\
VVD of the hypertonic type* & 13.95 & $0.83-232.12$ & 17.07 & $0.95-304.12$ \\
VVD of the mixed type* & 8.08 & $0.46-141.53$ & 8.97 & $0.47-167.9$ \\
mitral valve prolapse (MVP) & 1.45 & $0.39-5.43$ & 1.52 & $0.35-6.56$ \\
varicose veins & 3.67 & $0.18-74.21$ & 3.81 & $0.17-82.03$ \\
hypertensive disease & 3.67 & $0.18-74.21$ & 3.81 & $0.17-82.03$ \\
\hline Gastrointestinal tract & 1.75 & $0.67-4.51$ & 2.00 & $0.63-6.31$ \\
pathology & & & & \\
\hline Endocrinopathies & & & & \\
and metabolic disorders: & $\mathbf{6 . 5 6}$ & $1.62-26.46$ & $\mathbf{9 . 9 0}$ & $2.11-46.28$ \\
Obesity & $\mathbf{1 . 8 9}$ & $0.74-4.82$ & $\mathbf{2 . 2 2}$ & $0.71-6.97$ \\
Thyroid pathology & $\mathbf{2 . 2 0}$ & $0.09-52.55$ & $\mathbf{2 . 2 4}$ & $0.08-56.68$ \\
\hline Diabetes & 1.85 & $1.07-3.19$ & 3.05 & $1.22-7.63$ \\
\hline Urinary system pathology & 4.01 & $0.94-16.96$ & 4.90 & $1.01-23.76$ \\
\hline ABO-sensitization & \multicolumn{3}{|l}{} \\
\hline
\end{tabular}

Gastrointestinal track pathology: Digestive system pathology was diagnosed in $12(25 \%)$ women of the GH group, and in 5 women (14,3\%) of the control group.

Endocrinopathies and metabolic disorders: Obesity occurred in $18(37.5 \%)$ cases of within the GH group, and in $2(5.7 \%)$ cases of the control group (RR -6.56 , OR $9.90)$; thyroid pathology was observed in $13(27 \%)$ patients in the GH group, and in $5(14.3 \%)$ cases of the control group $(\mathrm{RR}-1,89, \mathrm{OR}-2.22)$ diabetes was observed in $1(2.1 \%)$ woman of $\mathrm{GH}$ group $(\mathrm{RR}-2.20)$.

Urinary system pathology: This was encountered in 28 pregnant women $(58,3 \%)$ of the GH group and in $11(31,4 \%)$ pregnant women of the control group (RR -1.85 , OR $-3.05)$.

ABO-sensitization: This occurred in 11 women $(22.9 \%)$ of the GH group, and $2(5.7 \%)$ pregnant women of the control group (RR - 4.01, OR - 4.90).

\section{DISCUSSION}

Unlike the previous researchers [4,7], who considered the highest risk factors of $\mathrm{GH}$ development to be primipregnancy, the data of our study show that consecutively pregnant women have the highest risk, while those of primipregnancy has the lowest. However, like the other authors $[2,7]$, we concluded the increased risk of GH development came as a result of age ( $\leq 18$ years old, $31-35$ years old and over 35 years old), city residence, unmarried status, gestational hypertension history and the presence of cardiovascular system diseases.

According to our study results, the risk of GH development is significantly higher in pregnant women with postsecondary education, in unemployed women and in women whose pregnancy is complicated by the threat of termination.

What is more, we discovered that, among extragenital pathology, GM occurrence is significantly enhanced by the presence of VVD, varicose veins, diabetes, urinary tract pathology, ABO-sensitization and obesity. Women considered overweight $\left(\mathrm{BMI}>29 \mathrm{~kg} / \mathrm{m}^{2}\right)$ also have a high risk of $\mathrm{GH}$ development $[2,8]$; according to our data, the risk of $\mathrm{GH}$ development is increased by 6.56 times at BMI $>30 \mathrm{~kg} / \mathrm{m}^{2}$.

In summary, in order to predict gestational hypertension development, it is necessary to identify these factors in the pregnant during the process of their registration in prenatal clinics so as to form a high-risk GH group and to undertake preventive measures.

\section{CONCLUSIONS AND PERSPECTIVES FOR FURTHER DEVELOPMENT}

The data of our study show that the GH development is closely linked with such risk factors as: age ( $\leq 18$ years old, 31-35 years old and over 35 years old), unmarried status, living in a city/town, post-secondary education, unemployment, obesity, first labor in consecutively pregnant women, the threat of pregnancy termination, gestational hypertension history, the presence of cardiovascular system diseases, urinary tract pathology, varicose veins and ABO-sensitization. 
A perspective way of further research is the prediction of GH development long before the clinical complications manifest.

\section{REFERENCES}

1. Coonrod, D.V. et al.: Ethnicity, acculturation and obstetric outcomes. J. Reprod Med., 1, 49, 2004.

2. Kosova A.S. (2015). Preeclampsia: modern approaches for prediction and prevention. Autoabstract. Thesis candidate of medical science. Orel.
3. Ohapkyn M.B. at al.: Preeclampsia: hemodynamic adaptation syndrome. J. AG-info., 9, 3, 2002.

4. Pristrom A.M. (2011). Arterial hypertension of pregnant: diagnosis, classification, clinical forms. Medisont, Minsk.

5. Savelyeva G.M.: Gestosis in modern obstetrics. Internatational medical journal, 50, 1, 2000.

6. Shifman E.M. (2002). Preeclampsia, eclampsia, HELLP-syndrome. IntelTek, Petrozavodsk.

7. Syngelaki, A. et al.: Body mass indexat 11-13 weeks gestation and pregnancy complications. Fetal Diagn Ther., 250, 30, 2011.

8. WHO (2005). Reduction of maternal mortality. WHO, Geneva. 